\title{
ANALISIS FAKTOR-FAKTOR YANG BERHUBUNGAN DENGAN STATUS IMUNISASI DASAR LENGKAP PADA BAYI DI DESA MANGUNREJO KECAMATAN NGADILUWIH KABUPATEN KEDIRI TAHUN 2018
}

\author{
Machsun $^{1}$, Yuda Ari Susanti ${ }^{2}$ \\ Email: Machsun_s@yahoo.com ${ }^{1}$, arisusanti.yuda@gmail.com²
}

\begin{abstract}
ABSTRAK
Imunisasi merupakan upaya pencegahan primer yang efektif untuk mencegah terjangkitnya penyakit infeksi yang dapat dicegah dengan imunisasi. Program Pengembangan Imunisasi (PPI) telah dicanangkan oleh WHO sejak tahun 1974 dengan tujuh penyakit target yaitu difteri, tetanus, pertusis, polio, campak, tuberkulosis, dan hepatitis B. Cakupan imunisasi yang rendah menjadi indikator terjadinya kematian akibat PD3I. Oleh karena itu salah satu program yang telah terbukti efektif untuk menurunkan angka kesakitan dan kematian akibat PD3I adalah imunisasi. Hal ini sejalan dengan kesepakatan MDG's, dimana untuk mencapai penurunan angka kematian bayi ditandai dengan peningkatan cakupan imunisasi terutama dilihat dari angka cakupan imunisasi campak (WHO, 2008). Hal itu dikarenakan campak adalah imunisasi yang terakhir untuk imunisasi dasar dan merupakan imunisasi yang cukup jauh jaraknya dari imunisasi sebelumnya (yaitu polio 4 pada usia 4 bulan dan campak pada usia 9 bulan) sehingga dapat menjadi indikator tercapainya kondisi Universal Child Immunization (UCI). Tujuan jangka panjang penelitian ini adalah diharapkan dapat menambah pengetahuan bagi pengembangan penelitian terutama dalam ilmu kesehatan masyarakat. Dengan adanya penelitian ini diharapkan dapat menekan terjangkitnya penyakit dan menekan angka resiko kematian bayi. Sehingga pada akhirnya dapat meningkatkan derajat kesehatan masyarakat. Tujuan penelitian ini adalah ingin mengetahui faktorfaktor yang berhubungan dengan status imunisasi dasar lengkap pada bayi di Desa Mangunrejo Kecamatan Ngadiluwih Kabupaten Kediri. Penelitian dilaksanakan mulai pada bulan Februari s/d Mei 2018. Sampel dari penelitian ini adalah semua ibu yang mempunyai bayi umur $12 \mathrm{~s} / \mathrm{d} 24$ bulan yang bersedia menjadi responden. Analisis data menggunakan uji Chi Squere. Hasil penelitian di desa Mangunrejo Kecamatan Ngadiluwih Kabupaten Kediri menunjukkan bahwa adanya hubungan antara pengetahuan ibu dengan status imunisasi dasar lengkap bayi dengan $\mathrm{p}$ value sebesar $0,013<$ $(0,05)$, Adanya hubungan antara status pekerjaan ibu dengan status imunisasi dasar lengkap bayi dengan $\mathrm{p}$ value sebesar $0,019<\alpha(0,05)$ dan Adanya hubungan antara pendapatan keluarga dengan status imunisasi dasar lengkap bayi dengan $\mathrm{p}$ value sebesar $0,004<\alpha(0,05)$.
\end{abstract}

Kata kunci: imunisasi dasar

\section{ABSTRACT}

Immunization is considered as an effective primary prevention to some certain infectious diseases effectively. WHO has established Immunization Development Program (IDP) since 1974 with seven kinds of disease as the targets: diphtheria, tetanus, pertusis, polio, measles, tuberculosis and hepatitis B. Low immunization coverage has become the indicator of the mortality occurance as the result of PD3I. Thus, one of the programs which has been proved effectively in decreasing both sickness and mortality caused by PD3I is immunization. It conforms to the MDG's agreement in which it is stated that in order to reach desreasing number of infant mortality is marked by the increasing immunization coverage, especially by the measles immunization coverage numbers (WHO, 2008). Since the measles immunization is the last basic one given to the babies and which has the longest space from the former ones (polio 4, given to the age of 4 months, while measles is given to the age of 9 months) it can be taken as the indicator that the condition of universal child immunization has been fulfilled. The purpose of this study is to improve the knowledge in research development, especially knowledge of public health. This is also aimed to minimize the risk of infant mortality. And, as the result, public health level can be improved. The significance of this study to find out factors related to the status of complete basic immunization for infants in Mangunrejo village, Ngadiluwih District, Kediri Regency. This research has been carried out since February to May 2018. Samples in this research are mothers with 12-24 months-baby as the respondents. The data analysis used here is Chi Squere Test. The result of the research in Mangunrejo village shows that there is relationship between the immunization status with mothers' background. Educated mothers shows $p$ value $0.013<\alpha(0.05)$ has had their babies given a complete basic immunization, and working mothers shows $p$ value 0.019 $<\alpha(0.05)$, while family income shows p value $0.004<\alpha(0,05)$.

Key words :basic immunization 
Imunisasi merupakan upaya pencegahan primer yang efektif untuk mencegah terjangkitnya penyakit infeksi yang dapat dicegah dengan imunisasi. Program Pengembangan Imunisasi (PPI) telah dicanangkan oleh WHO sejak tahun 1974 dengan tujuh penyakit target yaitu difteri, tetanus, pertusis, polio, campak, tuberkulosis, dan hepatitis B.

Menurut Depkes RI tahun 2000 (SDKI, 2003) diterangkan bahwa Program Pengembangan Imunisasi kemudian disingkat dengan PPI, yang dicanangkan oleh Departemen Kesehatan tahun 1977 menganjurkan agar semua anak mendapat imunisasi terhadap enam penyakit anak yang utama bisa dicegah dengan imunisasi: satu kali imunisasi BCG terhadap tuberkulosis; tiga kali imunisasi DPT untuk mencegah difteri, pertusis dan tetanus; empat kali imunisasi polio; dan satu kali imunisasi campak. Pada tahun 1997, program imunisasi dikembangkan dengan memasukan tiga dosis vaksin Hepatitis B.

Selanjutnya dalam Keputusan Kementerian Kesehatan Republik Indonesia Nomor 482/MENKES/SK/IV/2010 tentang Gerakan Akselerasi Imunisasi Nasional, Universal Child Immunization 2010-2014 (Riskesdas, 2013), diterangkan bahwa Imunisasi merupakan upaya efektif untuk menurunkan angka kematian anak yang merupakan salah satu tujuan dari Millenium Development Goals (MDGs). Tujuan utama kegiatan imunisasi adalah untuk menurunkan angka kesakitan dan kematian akibat Penyakit yang Dapat Dicegah Dengan Imunisasi (PD3I). PD3I adalah penyakit-penyakit menular yang sangat potensial untuk menimbulkan wabah dan kematian terutama pada balita. Sebelum kegiatan imunisasi dipergunakan secara luas di dunia, banyak anak yang terinfeksi penyakit seperti: penyakit polio, campak, pertusis, dan difteri yang dapat berakibat kematian dan kecacatan. Dengan keadaan tersebut akan diperberat bila disertai dengan gizi buruk dan menyebabkan peningkatan Case Fatality Rate (CFR) penyakit PD3I tersebut.

Cakupan imunisasi yang rendah menjadi indikator terjadinya kematian akibat PD3I. Oleh karena itu salah satu program yang telah terbukti efektif untuk menurunkan angka kesakitan dan kematian akibat PD3I adalah imunisasi. Hal ini sejalan dengan kesepakatan MDG's, dimana untuk mencapai penurunan angka kematian bayi ditandai dengan peningkatan cakupan imunisasi terutama dilihat dari angka cakupan imunisasi campak (WHO, 2008). Hal itu dikarenakan campak adalah imunisasi yang terakhir untuk imunisasi dasar dan merupakan imunisasi yang cukup jauh jaraknya dari imunisasi sebelumnya (yaitu polio 4 pada usia 4 bulan dan campak pada usia 9 bulan) sehingga dapat menjadi indikator tercapainya kondisi Universal Child Immunization $(U C I)$.

Penyelenggaraan kegiatan imunisasi sejak tahun 2005 berpedoman pada Keputusan Menteri Kesehatan Nomor 1611/Menkes/SK/XI/2005 tentang Pedoman Penyelenggaraan Imunisasi. Salah satu tujuannya adalah tercapainya target Universal Child Immunization (UCI) yaitu cakupan imunisasi dasar lengkap minimal $80 \%$ secara merata pada bayi di $100 \%$ Desa/Kelurahan pada tahun 2010, jadi setiap desa harus mencapai UCI yaitu cakupan imunisasi dasar bayi lengkap minimal $80 \%$. Pencapaian Desa/Kelurahan UCI tahun 2008 baru mencapai $68,2 \%$, padahal target nasional pada tahun 2014 ialah 100\% UCI desa/kelurahan, artinya pada akhir tahun 2014 seluruh desa/kelurahan harus sudah mencapai UCI. Indikator keberhasilan GAIN UCI megacu pada RPJMN tahun 2010-2014 mencapai UCI desa/kelurahan 95\% pada tahun 2013 (Depkes RI, 2010).

Berdasarkan fenomena di atas, maka peneliti ingin menggali lebih dalam faktor-fator yang berhubungan dengan status imunisasi dasar lengkap pada bayi di Desa Mangunrejo Kecamatan Ngadiluwih Kabupaten Kediri.

Berdasarkan latar belakang diatas, maka dapat dirumuskan permasalahan penelitian sebagai berikut : "Apakah faktor-faktor yang berhubungan dengan status imunisasi dasar lengkap pada bayi usia 12sampai dengan 24 bulan di Desa Mangunrejo Kec. Ngadiluwih Kab. Kediri Tahun 2018 ?

\section{METODE}

Penelitian ini merupakan penelitian analitik korelasional dengan rancangan cross sectional. Penelitian ini bertujuan untuk mengungkapkan hubungan korelatif antara variabel dependen dan variabel independen.

Penelitian ini dilakukan di Desa Mangunrejo Kec. Ngadiluwih Kabupaten Kediri. Sedangkan sampel penelitiaaan ini adalah semua ibu yang mempunyai anak balita usia 12 sampai 24 bulan yang bersedia menjadi responden yaitu berjumlah 46 orang.

Dalam penelitian ini terbagi menjadi beberapa bagian variabel antara lain yaitu: Variabel dependen yaitu Status Imunisasi Dasar Lengkap, sedangkan Variabel independen yaitu pengetahuan Ibu, Status Pekerjaan Ibu, pendapatan keluarga. Analisis data menggunakan uji Chi Square. 


\section{HASIL}

\section{Hubungan Pengetahuan Ibu Dengan Status Imunisasi Dasar Lengkap Pada Bayi}

Hubungan pengetahuan ibu dengan status imunisasi dasar lengkap pada bayi dapat dilihat pada tabel berikut :

Tabel 1. Hubungan antara pengetahuan ibu dengan satus imunisasi dasar pada bayi di Desa Mangunrejo Kec. Ngadiluwih Kabupaten Kediri tahun 2018

\begin{tabular}{|c|c|c|c|c|c|c|c|}
\hline \multirow{3}{*}{$\begin{array}{c}\text { Pengetahuan } \\
\text { Ibu }\end{array}$} & \multicolumn{4}{|c|}{ Status Imunisasi } & \multirow{2}{*}{\multicolumn{2}{|c|}{ Total }} & \\
\hline & \multicolumn{2}{|c|}{ Lengkap } & \multicolumn{2}{|c|}{$\begin{array}{c}\text { Tidak } \\
\text { Lengkap }\end{array}$} & & & $p$ value \\
\hline & $\mathbf{F}$ & $\%$ & $\mathbf{F}$ & $\%$ & $\mathrm{~F}$ & $\%$ & \\
\hline Baik & 25 & 86.2 & 4 & 13.3 & 29 & 100 & 0.013 \\
\hline Kurang & 9 & 52.9 & 8 & 47.1 & 17 & 100 & \\
\hline
\end{tabular}

Tabel di atas menunjukkan bahwa dari $29 \mathrm{ibu}$ yang memiliki pengetahuan baik yang status imunisasi dasar bayinya lengkap sebesar $86.2 \%$ sedangkan yang stutus imunisasi dasar bayinya tidak lengkap sebesar $13.3 \%$. Kemudian dari 17 ibu yang memiliki pengetahuan kurang yang status imunisasi dasar bayinya lengkap sebesar $52.9 \%$ sedangkan yang stutus imunisasi dasar bayinya tidak lengkap sebesar $47.1 \%$.

Berdasarkan hasil uji chi-square diperoleh $\mathrm{p}$ value $=0.013<\alpha(0.05)$, berarti Ho ditolak sehingga dapat disimpulkan ada hubungan antara pengetahuan ibu dengan status imunisasi dasar lengkap pada bayi.

\section{Hubungan Status Pekerjaan Dengan Status Imunisasi Dasar Lengkap Pada Bayi}

Hubungan status pekerjaan ibu dengan status imunisasi dasar pada bayi dapat dilihat pada tabel berikut :

Tabel 2. Crosstab status pekerjaan ibu dengan satus imunisasi dasar pada bayi di Desa Mangunrejo Kec. Ngadiluwih Kabupaten Kediri tahun 2018

\begin{tabular}{lrrrrrrr}
\hline \multirow{2}{*}{$\begin{array}{c}\text { Status } \\
\text { Pekerjaan } \\
\text { Ibu }\end{array}$} & \multicolumn{4}{c}{ Status Imunisasi } & Total & p value \\
\cline { 2 - 6 } & Lengkap & $\begin{array}{c}\text { Tidak } \\
\text { Lengkap }\end{array}$ & & & & \\
\cline { 2 - 7 } & F & \multicolumn{1}{c}{ F } & \% & F & $\%$ & \\
\hline Bekerja & 15 & 60 & 10 & 40 & 25 & 100 & 0,019 \\
Tidak & 19 & 90.5 & 2 & 9.5 & 21 & 100 & \\
Bekerja & & & & & & & \\
\hline
\end{tabular}

Tabel diatas menunjukkan bahwa dari $25 \mathrm{ibu}$ yang bekerja yang status imunisasi dasar bayinya lengkap sebesar $60 \%$ sedangkan yang status imunisasi dasar bayinya tidak lengkap sebesar 40
$\%$. Kemudian dari 21 ibu yang tidak bekerja yang status imunisasi dasar bayinya lengkap sebesar $90.5 \%$ sedangkan yang stutus imunisasi dasar bayinya tidak lengkap sebesar $9.5 \%$.

Berdasarkan hasil uji chi-square diperoleh $\mathrm{p}$ value $=0.019<\alpha(0.05)$, berarti Ho ditolak sehingga dapat disimpulkan ada hubungan antara status pekerjaan ibu dengan status imunisasi dasar lengkap pada bayi.

\section{Hubungan Pendapatan Keluarga Dengan Status Imunisasi Dasar Lengkap Pada Bayi}

Hubungan pendapatan keluarga dengan status imunisasi dasar pada bayi dapat dilihat pada tabel berikut :

Tabel 3.Crosstab pendapatan keluarga dengan satus imunisasi dasar pada bayi di Desa Mangunrejo Kec. Ngadiluwih Kabupaten Kediri Tahun 2018

\begin{tabular}{|c|c|c|c|c|c|c|c|}
\hline \multirow{3}{*}{$\begin{array}{l}\text { Pendapatan } \\
\text { Keluarga }\end{array}$} & \multicolumn{4}{|c|}{ Status Imunisasi } & \multirow{2}{*}{\multicolumn{2}{|c|}{ Total }} & \multirow{3}{*}{ p value } \\
\hline & \multicolumn{2}{|c|}{ Lengkap } & \multicolumn{2}{|c|}{$\begin{array}{c}\text { Tidak } \\
\text { Lengkap }\end{array}$} & & & \\
\hline & $\mathbf{F}$ & $\%$ & & $\%$ & $\mathrm{~F}$ & $\%$ & \\
\hline Cukup & 19 & 95 & 1 & 5 & 20 & 100 & 0,004 \\
\hline Kurang & 15 & 57.7 & 11 & 42.3 & 26 & 100 & \\
\hline
\end{tabular}

Tabel diatas menunjukkan bahwa dari $20 \mathrm{ibu}$ yang mempunyai pendapatan cukup yang status imunisasi dasar bayinya lengkap sebesar $95 \%$ sedangkan yang status imunisasi dasar bayinya tidak lengkap sebesar $5 \%$. Kemudian dari $26 \mathrm{ibu}$ yang mempunyai pendapatan kurang yang status imunisasi dasar bayinya lengkap sebesar $57.7 \%$ sedangkan yang stutus imunisasi dasar bayinya tidak lengkap sebesar $42.3 \%$.

Berdasarkan hasil uji chi-square diperoleh $\mathrm{p}$ value $=0.004<\alpha(0.05)$, berarti Ho ditolak sehingga dapat disimpulkan ada hubungan antara pendapatan keluarga dengan status imunisasi dasar lengkap pada bayi.

\section{PEMBAHASAN}

\section{Hubungan Pengetahuan Ibu Dengan Status Imunisasi Dasar Lengkap Pada Bayi}

Perhitungan analisis dengan Uji Chi-Square pada faktor pengetahuan ibu menunjukkan angka $\mathrm{p}$ value sebesar $0,013<\alpha(0,05)$, sehingga $\mathrm{H}_{0}$ ditolak, yakni berarti ada hubungan antara pengetahuan ibu dengan status imunisasi dasar lengkap pada bayi di Desa Mangunrejo Kecamatan Mgadiluwih Kabupaten Kediri. Pengetahuan merupakan tahap awal di mana subjek mulai mengenal ide baru serta belajar memahami yang pada akhirnya dapat mengubah perilaku. Semakin baik pengetahuan ibu tentang 
pemberian imunisasi maka akan memberikan respons yang positif yaitu meningkatkan kemauan ibu untuk memberikan imunisasi dasar pada bayi.

Pengetahuan ibu mempengaruhi keyakinan dan sikap ibu dalam kepatuhannya terhadap pemberian imunisasi. Kepatuhan terhadap perilaku pencegahan yang berkaitan dengan dunia medis merupakan fungsi dari keyakinan tentang kesehatan, ancaman yang dirasakan, persepsi kekebalan, pertimbangan mengenai hambatan atau kerugian (misalnya biaya dan waktu), serta keuntungan yaitu efektivitas dari anjuran medis tersebut (Smet dalam Rizani, 2009).

Pengetahuan yang baik dapat mempengaruhi terjadinya perubahan perilaku. Perilaku dapat diubah dengan mengubah pengetahuan dan sikap. Pengetahuan yang baik dapat mempengaruhi sikap dan terjadinya perubahan perilaku. Pengetahuan adalah sesuatu yang perlu tetapi pada umumnya tidak cukup satu faktor dalam mengubah perilaku individu atau kelompok (Gust, 2004). Pendapat Notoatmodjo (2010) menyatakan bahwa tindakan seseorang terhadap masalah kesehatan pada dasarnya akan dipengaruhi oleh pengetahuan seseorang tentang masalah tersebut.

Peneliti menganalisis bahwa pengetahuan tidak selalu didapat dari tingginya pendidikan formal yang diperoleh, akan tetapi pengetahuan juga dapat diperoleh dari media massa, pengalaman pribadi ataupun pengalaman orang lain. Suatu pengetahuan merupakan domain yang sangat penting untuk terbentuknya suatu tindakan, semakin baik pengetahuan ibu maka akan semakin tinggi pula peluang ibu untuk kelengkapan imunisasi pada bayinya.

Berdasarkan pendapat itu peneliti menyarankan petugas kesehatan yang ada di Desa Mangunrejo Kecamatan Ngadiluwih Kabupaten Kediri untuk lebih meningkatkan lagi upaya peningkatan pengetahuan masyarakat serta kader posyandu mengenai imunisasi dengan cara meningkatkan penyuluhan-penyuluhan. Bisa dilakukan dengan kegiatan puskesmas yang terjadwal ataupun pada kegiatan posyandu yang rutin dilakukan setiap bulan.

\section{Hubungan Status Pekerjaan Ibu dengan Status Imunisasi Dasar Lengkappada Bayi}

Perhitungan analisis dengan Uji Chi-Square pada faktor Status Pekerjaan Ibu menunjukkan angka $\mathrm{p}$ value sebesar $0,019<\alpha(0,05)$, sehingga $\mathrm{H}_{0}$ ditolak, yakni berarti ada hubungan antara status pekerjaan ibu dengan status imunisasi dasar lengkap pada bayi di Desa Mangunrejo Kecamatan Mgadiluwih Kabupaten Kediri. Status pekerjaan ibu berkaitan dengan kesempatan dalam mengimunisasai anaknya. Seorang ibu yang tidak bekerja akan mempunyai kesempatan untuk mengimunisasikan anaknya dibanding dengan ibu yang bekerja. Pada ibu-ibu yang bekerja diluar rumah sering kali tidak mempunyai kesempatan untuk datang ke pelayanan imunisasi karena mungkin saat dilakukan pelayanan imunisasi ibu masih bekerja ditempat kerjanya. Sering juga ibu yang terlalu sibuk dengan urusan pekerjaannya lupa akan jadwal imunisasi anaknya (Notoatmodjo, 2003).

Hasil analisis menunjukkan bahwa pekerjaan dapat mempengaruhi ibu dalam memberikan kelengkapan imunisasi dasar pada bayinya. Karena pada ibu yang tidak bekerja akan lebih berpeluang memberikan imunisasi dasar pada bayi dari pada ibu yang bekerja.

Berdasarkan hal tersebut peniliti menyarankan untuk ibu-ibu yang bekerja yang memiliki bayi 12 s/d 24 bulan untuk segera mendatangi langsung ketempat pelayanan kesehatan seperti puskesmas, rumah sakit atau Bidan Praktek Swasta saat ibu memiliki waktu luang.

\section{Hubungan Status Pendapatan Keluarga dengan Status Imunisasi Dasar Lengkap pada Bayi}

Perhitungan analisis dengan Uji Chi-Square pada faktor pendapatan keluarga menunjukkan angka $p$ value sebesar $0,004<\alpha(0,05)$, sehingga $\mathrm{H}_{0}$ ditolak, yakni berarti ada hubungan antara pendapatan keluarga dengan status imunisasi dasar lengkap pada bayi di Desa Mangunrejo Kecamatan Ngadiluwih Kabupaten Kediri.

Analisis penelitian menunjukkan bahwa pendapatan keluarga atau status ekonomi seseorang akan mempengaruhi kemampuan seseorang untuk membiayai pelayanan kesehatan. Sering kali seseorang kalau sedang menderita sakit atau keluarganya yang sakit tidak dibawa ke pelayanan kesehatan karena tidak mampu dalam hal pembiayaan. Begitu pula ddengan masalah imunisasi, bias jadi seorang ibu ingin sekali mengimunisasikan anak-anakya akan tetapi tidak jadi karena tidak punya biaya .

\section{PENUTUP}

Kesimpulan yang diperoleh dari penelitian ini yaitu 1) adanya hubungan antara pengetahuan ibu dengan status imunisasi dasar lengkap bayi di Desa Mangunrejo Kecamatan Ngadiluwih Kabupaten Kediri dengan p value sebesar 0,013 < $(0,05), 2)$ adanya hubungan antara status pekerjaan ibu dengan status imunisasi dasar lengkap bayi di Desa Mangunrejo Kecamatan Ngadiluwih Kabupaten Kediri dengan $\mathrm{p}$ value 
sebesar $0,019<(0,05)$, dan 3$)$ adanya hubungan antara pendapatan keluarga dengan status imunisasi dasar lengkap bayi di desa mangunrejo kecamatan ngadiluwih kabupaten kediri dengan $p$ value sebesar $0,013<(0,05)$. Saran yang penulis berikan tenaga kesehatan, kader, dan perangkat desa yaitu diharapkan mampu menjalin komunikasi yang baik tidak hanya kepada ibu yang memiliki bayi/balita, akan tetapi juga kepada anggota keluarga yang lain. Apabila anggota keluarga yang lain dilibatkan, diharapkan dapat meningkatkan kepedulian sehingga dapat meningkatkan cakupan imunisasi dasar pada bayi. Masyarakat perlu diberikan motivasi untuk memanfaatkan Puskesmas, Posyandu, dan tempat pelayanan kesehatan yang terdekat sehingga dapat berpartisipasi mendukung program imunisasi. Selain itu masyarakat terutama yang memiliki bayi usia 12 - 24 bulan diharapkan memanfaatkan Puskesmas, Posyandu, dan tempat pelayanan kesehatan yang terdekat sehingga dapat berpartisipasi mendukung program imunisasi khususnya imunisasi dasar pada bayi, sehingga terhindar dari penyakit.

\section{DAFTAR PUSTAKA}

Aziz Alimun Hidayat, 2009. Ilmu Kesehatan Anak, Salemba Medika: Jakarta
Achmadi, Umar Fahmi. 2006. Imunisasi. Mengapa perlu?Jakarta:Buku Kompas.

Abraham, Charles. 1997. Prinsip psikologi untuk perawat. Jakarta: EGC

Depkes RI. 2005. Pedoman Teknis Imunisasi Tingkat Puskesmas. Jakarta: Depkes RI, Ditjen P2PL

Hidayat Aziz Alimul, A. 2008. Pengantar Ilmu Kesehatan Anak Untuk Pendidikan Kebidanan, Jakarta: Salemba Medika.

Munib, Achmad, dkk. 2004. Pengantar Ilmu Pendidikan. Semarang: UPT MKK UNNES

Maryunani, Anik. 2010. Ilmu Kesehatan Anak dalam Kebidanan, Jakarta: CV. Trans Info.

Notoatmodjo, S. 2003 .Pendidikan dan Perilaku Kesehatan. Jakarta : PT. Rineka Cipta. . 2007. Promosi Kesehatan dan Ilmu Prilaku.Rineka Cipta. Jakarta. 2010.Ilmu Perilaku Kesehatan. Jakarta : PT Rineka Cipta

Ranuh,I.G.N.2008. Pedoman Imunisasi di Indonesia. Edisi ketiga.Jakarta: Badan Penerbit Ikatan Dokter Anak Indonesia

Suririnah. 2009. Buku Pintar Merawat Bayi 0-12 bulan, Gramedia Pustaka Utama: Jakarta.

Wiyono, Djoko. 2000. Manajemen Mutu Pelayanan Kesehatan, Teori, Strategi dan Aplikasi. Surabaya : Airlangga University Press. 